\title{
TEMPERATURE FIELD OF OPEN-STRUCTURED ABRASIVE BELT RAIL GRINDING USING FEM
}

\author{
Fan, W. G. ${ }^{* * *}$; Zhang, S. ; Wang, J. D. ; Wang, X. H. ${ }^{*} \&$ Wang, W. X. ${ }^{* * *, \#}$ \\ ${ }^{*}$ School of Mechanical, Electronic and Control Engineering, Beijing Jiaotong University, \\ Beijing 100044, P. R. China \\ ** Key Laboratory of Vehicle Advanced Manufacturing, Measuring and Control Technology, \\ Ministry of Education, Beijing Jiaotong University, Beijing 100044, P. R. China \\ ${ }^{* * * *}$ College of Mechanical Engineering, Chongqing University, Chongqing 400044, P. R. China \\ E-Mail:wgfan@bjtu.edu.cn, 18126026@bjtu.edu.cn, 18121260@bjtu.edu.cn, 17127804@bjtu.edu.cn, \\ wx.wang@cqu.edu.cn ( ${ }^{\#}$ Corresponding author)
}

\begin{abstract}
Abrasive belt rail grinding in open-loop structure (ABRG-O) has been recently proposed. However, its frictional heat leads to the risk of rail burning. In order to explore this grinding heat accumulation process, a 3D finite element model (FEM) of multi-abrasive scratching was established to analyse the grinding temperature field on the rail surface. The simulation results showed that the grinding temperature field was initially in the rectangular shape divided by chip grooves and then gradually became a strip shape with higher temperature in the middle. The increasing grinding force enlarged the magnitude and area of the temperature field. The force loaded at the centre of the grinding plate led to a more evenly distributed and longer high-temperature region. With the increase in chip grooves, the peak temperature rose. The study provides the theoretical basis for improving the grinding plate design and the intelligent setting of rail grinding mode.

(Received in November 2019, accepted in March 2020. This paper was with the authors 1 month for 1 revision.)
\end{abstract}

Key Words: Rail Grinding, Belt Grinding, Temperature Field, Abrasive Scratching, FEM

\section{INTRODUCTION}

Rail grinding has been recognized as the most effective way of railway maintenance in the world since it can remove various rail diseases, improve the wheel-rail relationship and extend the service life of rails [1-4]. With the rapid development of modern rail transit systems, the demand and complexity of railway maintenance are increased, thus promoting the applications of rail grinding equipment and intelligent technologies. Based on the merits of abrasive belt grinding [5,6], a novel fast rail grinding car based on open-loop structured belt grinding has been proposed for high-speed railways [7]. It aims to significantly improve the running speed and grinding efficiency under the premise of ensuring both grinding quality and accuracy. During the long-term heavy-duty rail grinding process, a large quantity of frictional heat is continuously generated on the railhead, so that the rail turns blue or even burns $[8,9]$. However, the quantitative control method of grinding temperature of openstructured belt grinding was seldom reported, so the intelligentization of abrasive belt rail grinding in open-loop structure (ABRG-O) remains a challenge. Thus, it is necessary to investigate the temperature distribution and critical factors influencing the grinding temperature field.

The heat distribution in the closed abrasive belt grinding process has been explored. In order to explore the influences of the geometric shape of each abrasive particle on local contact temperature, Jourani [10] established a 3D numerical model to determine the temperature distribution at the contact point between abrasives and workpieces. Wang et al. [11] experimentally investigated the grinding burn on nickel-based superalloy and found that belt speed and grinding force were sensitive factors for grinding burn. Huo et al. [12] conducted the FEM (finite element modelling) to explore the temperature field of dry belt 
grinding on titanium alloys based on a moving line heat source and revealed the comprehensive effect of three cutting factors on grinding temperature. The above studies indicated that the thermal imager could not precisely measure the temperature within the contact zone due to the severe cover caused by the grinding plate. Seriously, due to the lack of a long rail line and the complexity of thermocouples for detecting the grinding heat distribution, the temperature field of ABRG-O was not yet understood.

Inspired by the prominent role and wide application of FEM in the machining field [13-15], we conducted a thermal-mechanical coupled 3D FEM of multi-abrasive scratching to analyse the grinding temperature field on rail surface for ABRG-O in the study. Firstly, the heat transfer process for ABRG-O is introduced and the basic structure of the grinding unit and the heat transfer model are illustrated. Then, the finite element model of multi-abrasive scratching for thermal analysis is described in detail. Finally, the influences of grinding force, loading position, and the number of chip grooves on the grinding temperature field are investigated through the above-mentioned FEM.

\section{HEAT TRANSFER PROCESS IN ABRG-O}

\subsection{Basic structure of the grinding unit}

The grinding unit of ABRG-O (Fig. 1) proposed by Fan et al. [7] was designed for the fullenveloped profiling grinding. The length of the grinding plate was set to $300 \mathrm{~mm}$ to eliminate corrugation because the corrugation wavelength on the high-speed railway was concentrated in the range of $120 \mathrm{~mm} 150 \mathrm{~mm}$. Since the rail was composed of multiple arcs, the pressing plate was made into an internal concave shape that was the same as the profile of the railhead. Here, the angle range for high-speed line rail grinding was from $+20^{\circ}$ to $-20^{\circ}$, because the rail disease mainly occurred on the rail top. The width of the pressing plate was set as $55 \mathrm{~mm}$ to obtain the maximum enveloping range and allow the belt to get a larger grinding width. Several chip grooves in the middle of the pressing plate were used to remove chips and cool the grinding region. Besides, the grinding unit also consists of the winding wheel, the releasing wheel, pressing plate, the idler and the tensioning wheel, as shown in Fig. 1.

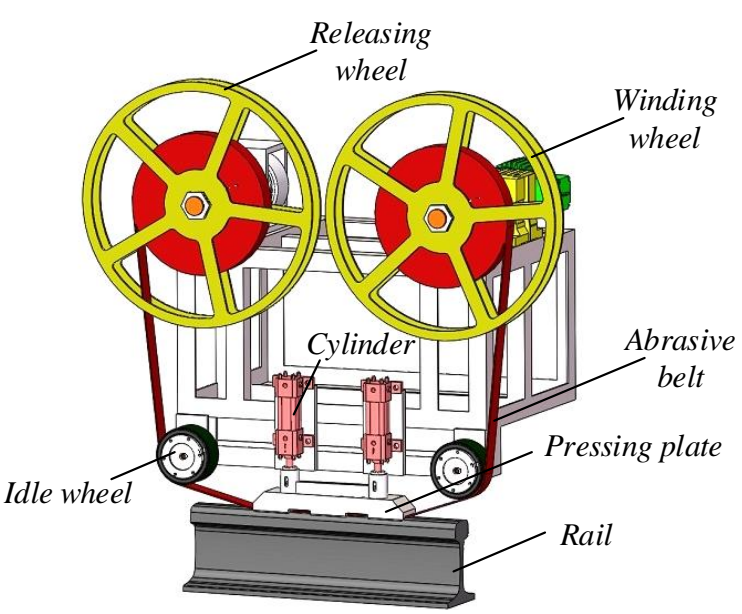

Figure 1: Digital model of the grinding unit.

\subsection{Heat transfer model}

A heat transfer phenomenon occurs around the interaction region between abrasives and rail during grinding. The heat transfer is the exchange of heat energy between objects, where the temperature difference exists. Its basic forms include heat conduction, heat convection and heat radiation. A simplified 3D heat transfer model was established for ABRG-O according to 
the designed grinding unit. As shown in Fig. 2, the model involves various factors: pressing plate, abrasive belt, rail and the ambient. The friction between the abrasive belt and the rail surface is the main reason for the temperature rise in the contact zone. The abrasive belt is updated backward with a velocity $\left(v_{1}\right)$ and moves forward with a velocity $\left(v_{2}\right)$ along the track alignment. The heat transfer process caused by belt grinding is described as follows. Friction heat in the contact zone enters the rail and abrasive belt via heat conduction. Heat on the rail surface dissipates into the ambient via heat convection and thermal radiation.

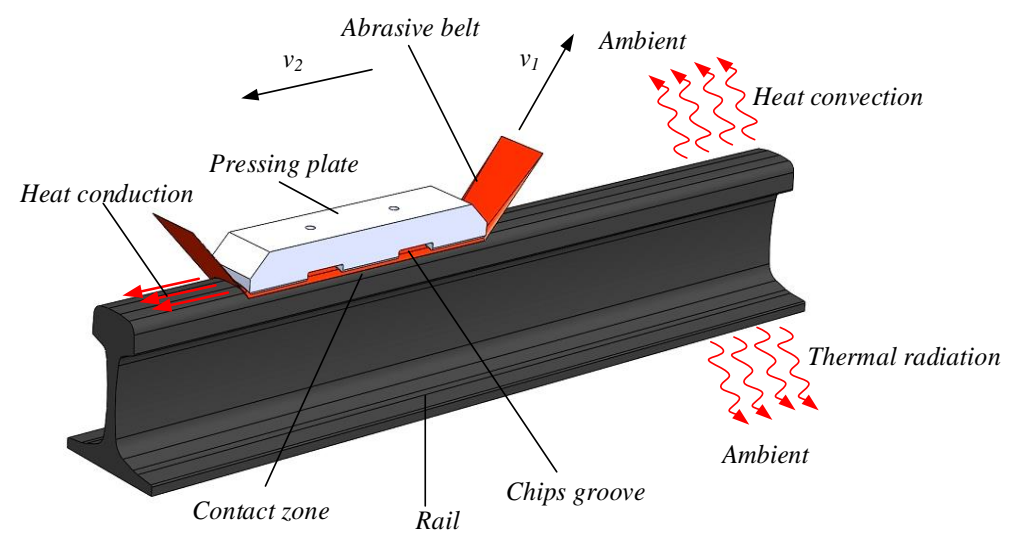

Figure 2: 3D thermal transfer model for ABRG-O.

\section{DESCRIPTIONS AND PARAMETERS OF NUMERICAL SIMULATION}

\subsection{Finite element model}

The first step in the establishment of finite element model is the pre-processing step of finite element simulation [16]. The standard rail designed for the velocity of $60 \mathrm{~kg} / \mathrm{m}$ was adopted for the simulation and the 3D model of the rail was established by Solidworks. The abrasive structure was usually a random polyhedron and difficult to be modelled, so it was simplified as a cone with a semi-spherical tip [17-19]. APDL parametric design language in ANSYS was used to program and design key parameters such as volume, shape and distribution density of abrasive particles of abrasive belt. Then, it was imported into ANSYS to generate 3D model of abrasive belt (Fig. 3). In order to reduce computation time and improve the simulation accuracy, 3D model of abrasive belt, rail and grinding plate were meshed by HYPERMESH. Fig. 4 illustrates the meshed results.

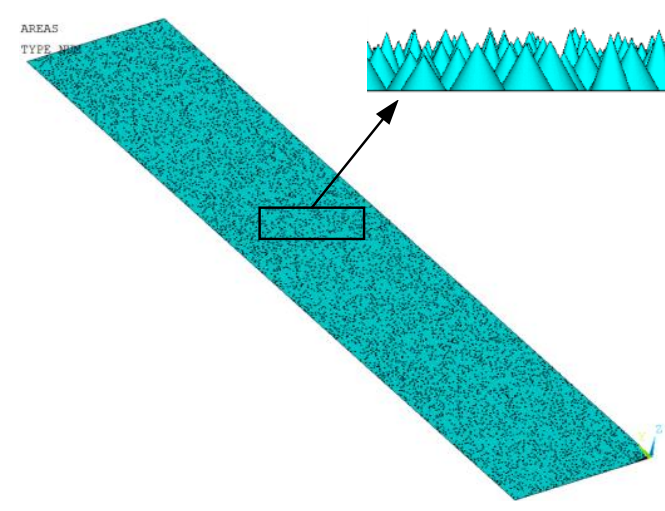

Figure 3: 3D geometry model of abrasive belt surface.

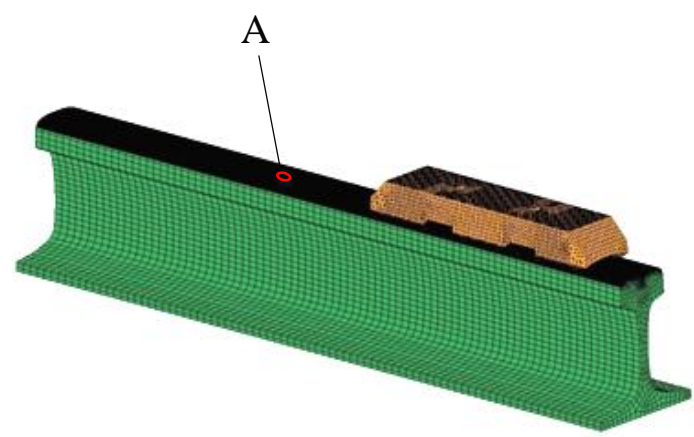

Figure 4: Meshed results of FEM.

All the models are symmetric models involving the thermodynamic coupling analysis with abundant grids, which lead to a large calculation load. So, a plane symmetric model (Fig. 5) was established for half of the grinding unit to reduce calculation time. 


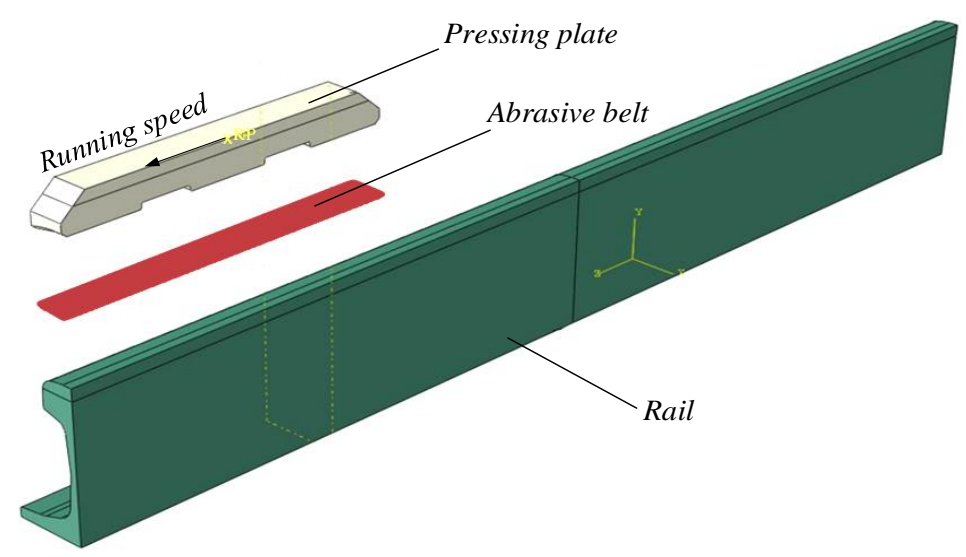

Figure 5: Symmetrical model of the grinding unit.

\subsection{Simulation parameters}

The mesh-divided model was imported into ABAQUS and then material properties were defined. The defined material properties include elastic modulus, thermal conductivity, density, Poisson's ratio, specific heat capacity and thermal expansion coefficient. The rail, base, and abrasive particles were respectively made of high manganese steel, polyester cloth, and alumina ceramics. The material parameters of each model are listed in Table I.

Table I: Material parameters.

\begin{tabular}{|c|c|c|c|c|c|c|}
\hline Properties & $\begin{array}{c}\text { Elastic } \\
\text { modulus }(\mathrm{MPa})\end{array}$ & $\begin{array}{c}\text { Density } \\
\left(\mathrm{kg} / \mathrm{m}^{3}\right)\end{array}$ & $\begin{array}{c}\text { Poisson's } \\
\text { ratio }\end{array}$ & $\begin{array}{c}\text { Specific heat } \\
(\mathrm{J} / \mathrm{kg} \cdot \mathrm{K})\end{array}$ & $\begin{array}{c}\text { Heat } \\
\text { conductivity } \\
(\mathrm{W} / \mathrm{m} \cdot \mathrm{K})\end{array}$ & $\begin{array}{c}\text { Thermal } \\
\text { expansively }\left(\times 10^{-6}\right)\end{array}$ \\
\hline Rail & $2.0 \mathrm{e} 5$ & $7.8 \mathrm{e} 3$ & 0.3 & 460 & 51 & 11 \\
\hline Belt base & $2.9 \mathrm{e} 3$ & $1.5 \mathrm{e} 3$ & 0.4 & 93 & 12 & 5.5 \\
\hline Abrasive & $3.7 \mathrm{e} 5$ & $3.9 \mathrm{e} 3$ & 0.24 & 780 & 23 & 7.7 \\
\hline
\end{tabular}

One contact pair was set to be between abrasives and rail surface, and the other pair was set to be between the back of belt and the lower surface of pressing plate. Rigid constraints were established between the upper surface and the reference point (RP in Fig. 5). The bottom of the rail was totally fixed on the ground. The grinding plate and abrasive belt shared the same running velocity along the track without any rotation. The movement of the pressing plate was applied on RP and the grinding force was applied on the upper surface of the pressing plate in the form of uniform pressure. Other environment settings are listed in Table II. Besides, the grinding force varied from 500 to $1500 \mathrm{~N}$ and was applied in two ways (in the middle and at two sides). The number of chip grooves was 2 to 4 .

Table II: Environment setting in the simulation.

\begin{tabular}{|c|l|c|}
\hline No. & \multicolumn{1}{|c|}{ Parameters } & Values \\
\hline 1 & Heat flow distribution coefficient to rail & 0.86 \\
\hline 2 & Conversion rate of friction heat & 1 \\
\hline 3 & Free-convection factor & 10 \\
\hline 4 & Thermal emissivity & 0.8 \\
\hline 5 & Initial temperature of components and the ambient & $20^{\circ} \mathrm{C}$ \\
\hline 6 & Friction coefficient & $0.2[20]$ \\
\hline 7 & Solver & Dynamic, Temp-disp, Explicit \\
\hline
\end{tabular}




\section{RESULTS AND DISCUSSION}

\subsection{Analysis of the temperature field on rail surface}

In this part, the running velocity $\left(v_{2}\right)$ was $50 \mathrm{~km} / \mathrm{h}$ and the grinding force was $500 \mathrm{~N}$. The overall temperature field corresponding to the shape of the contact zone between the plate and the belt is presented as 3 rectangular regions at the beginning. There was no temperature rise on the rail surface under the chip grooves. Then, the grooved portion had the low temperature, and finally became a long ribbon-shaped zone. Fig. 6 shows two high-temperature zones spaced by a thin strip-shaped lower-temperature zone, which is right at the junction of two surfaces with different curvatures on the railhead. The above zones might be interpreted as follows. The surface of the rail was composed of several curved surfaces with different curvatures and the junction was not as smooth as a single surface. The temperature field nephogram on the rail surface at 6 different intervals are shown in Fig. 6.

The surface temperature of the rail rose initially from $20^{\circ} \mathrm{C}$ to $119.8^{\circ} \mathrm{C}$ within $0.03 \mathrm{~s}$, then fluctuated within a small range and was gradually stabilized (Fig. 7). The grinding speed was so great that the rail surface immediately realized the highest temperature from the low temperature at the beginning. When the grinding heat and heat dissipation reached the equilibrium, the temperature field tended to be stable. The stable temperature of the current working condition was about $119^{\circ} \mathrm{C}$.

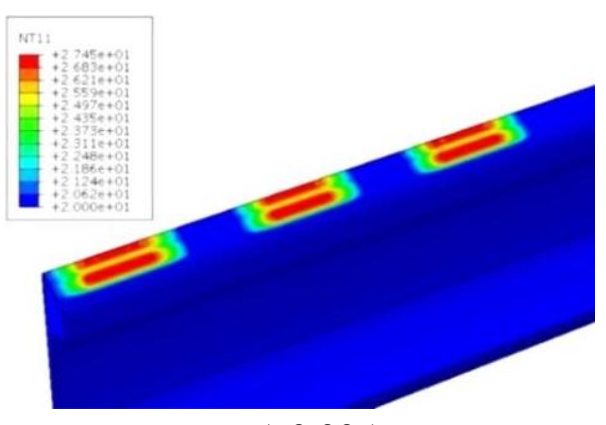

a) $0.005 \mathrm{~s}$

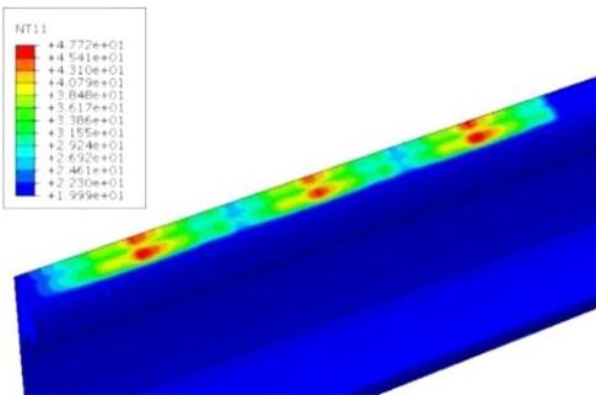

c) $0.015 \mathrm{~s}$

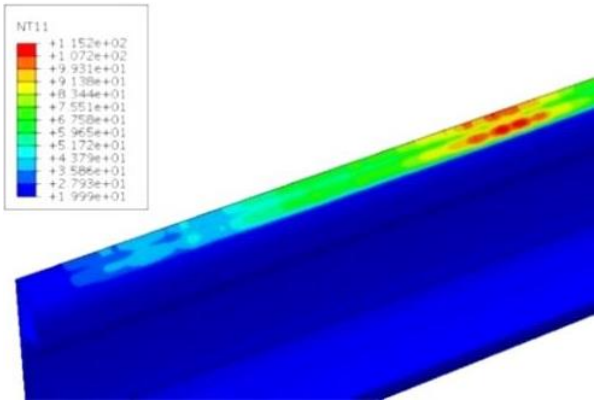

e) $0.03 \mathrm{~s}$

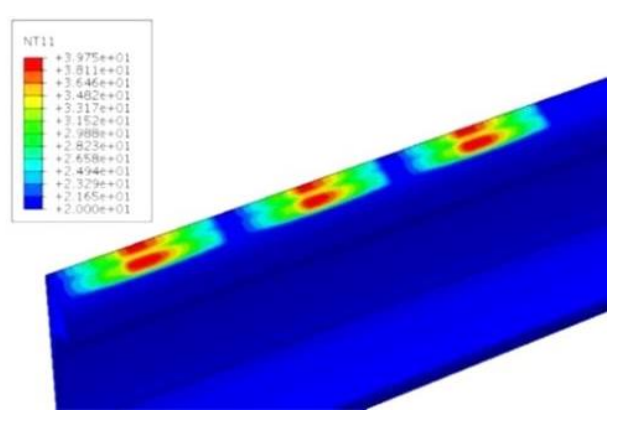

b) $0.01 \mathrm{~s}$

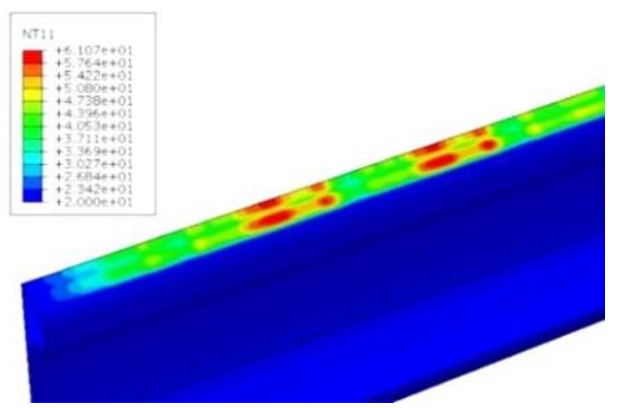

d) $0.02 \mathrm{~s}$

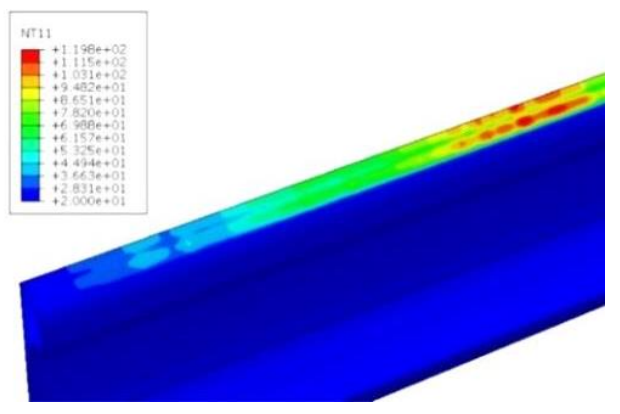

f) $0.04 \mathrm{~s}$

Figure 6: Grinding temperature field on the rail surface. 


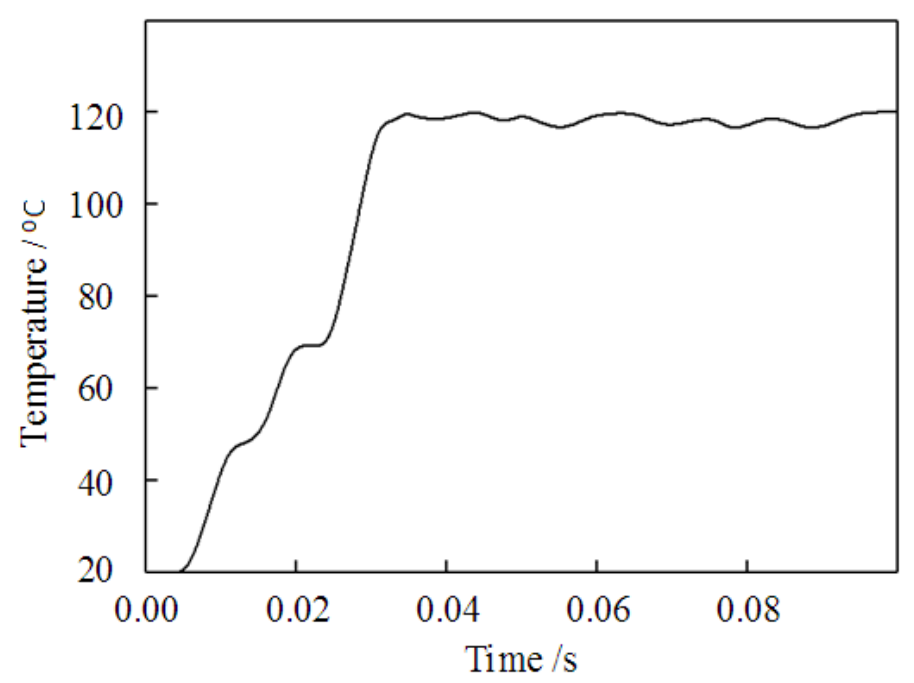

Figure 7: Maximum temperature curve of the rail surface.

The temperature variation of intermediate node A (marked in Fig. 4) on the rail surface was analysed. According to, it can be seen that after the grinding started, the temperature rose rapidly to the highest point around $119{ }^{\circ} \mathrm{C}$ within $0.04 \mathrm{~s}$, then gradually declined after $0.36 \mathrm{~s}$ and finally returned to ambient temperature (Fig. 8). Besides, the change of the temperature on the rail surface was exactly in line with the change of the displacement of the belt relative to the node during grinding.

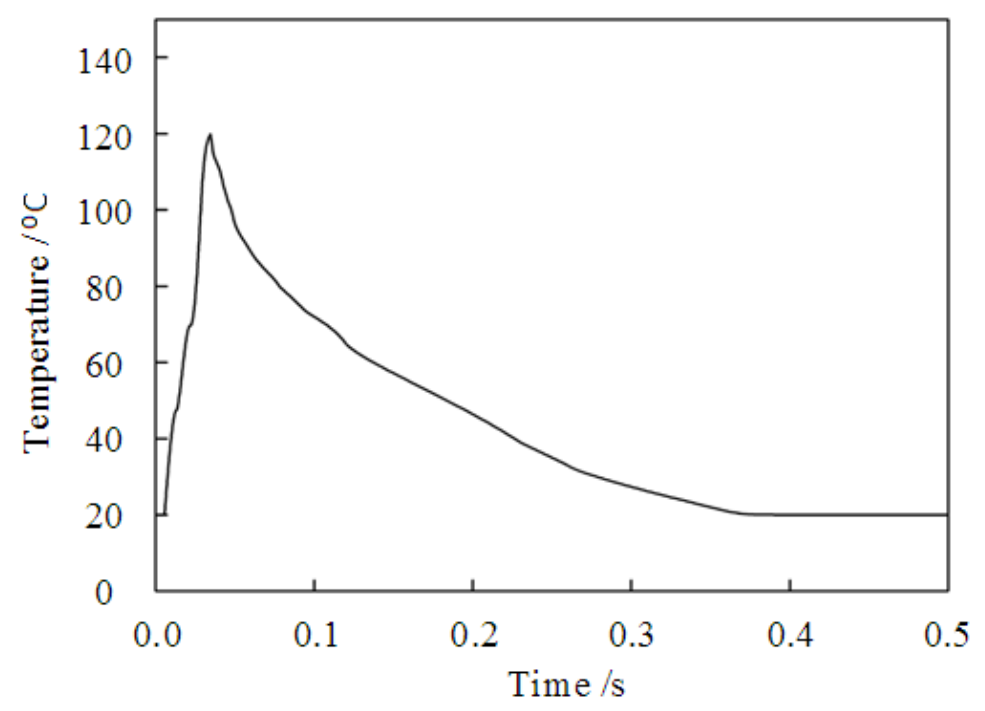

Figure 8: Temperature change diagram of the node A on the rail surface.

\subsection{Influence of grinding force on the temperature field}

The grinding speed was fixed at $50 \mathrm{~km} / \mathrm{h}$ and the uniform pressure of $750 \mathrm{~N}, 1000 \mathrm{~N}, 1250 \mathrm{~N}$ and $1500 \mathrm{~N}$ were set (Fig. 9). The rail surface temperature distribution obtained after simulation is shown in Fig. 8. With the increase in the grinding pressure, the overall temperature of the grinding contact area on the rail surface rose gradually. Under the above pressures, the maximum temperatures were $139.9^{\circ} \mathrm{C}, 168.8^{\circ} \mathrm{C}, 191.3^{\circ} \mathrm{C}$ and $211.7^{\circ} \mathrm{C}$, respectively. The overall temperature field was roughly rectangular in shape and less changed compared to its original shape. The high-temperature zone was prolonged with the increase in the grinding pressure. 


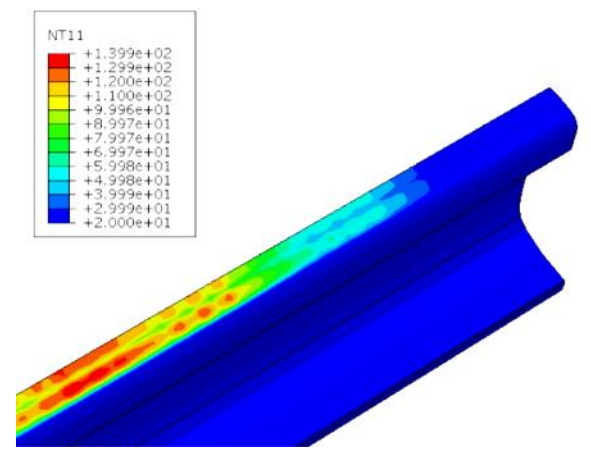

a) $750 \mathrm{~N}$

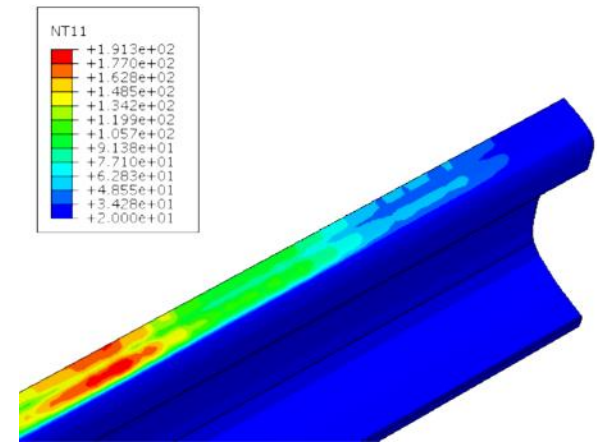

c) $1250 \mathrm{~N}$

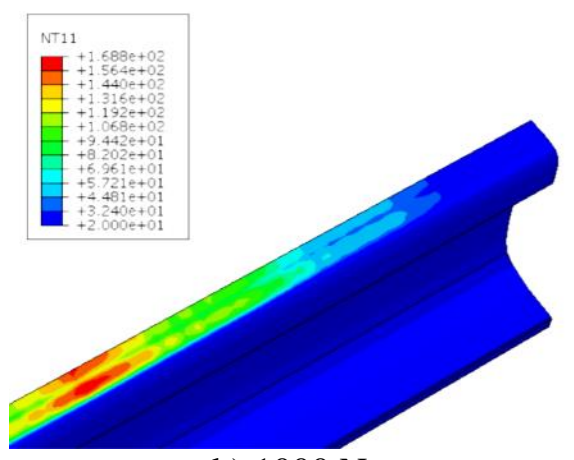

b) $1000 \mathrm{~N}$

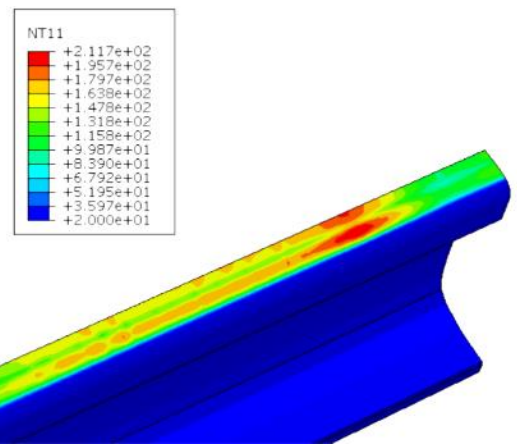

d) $1500 \mathrm{~N}$

Figure 9: Temperature distribution on the rail surface under different grinding forces.

During the grinding process, the rail surface temperature increased rapidly with the increase in the grinding pressure. The maximum temperature varied from $119.8{ }^{\circ} \mathrm{C}$ to $211.7^{\circ} \mathrm{C}$. When in the grinding pressure was increased by every $250 \mathrm{~N}$, the rail surface temperature was increased by about $20^{\circ} \mathrm{C}$. With the increase in the positive pressure, the grinding force, work, generated heat, and temperature increased (Fig. 10).

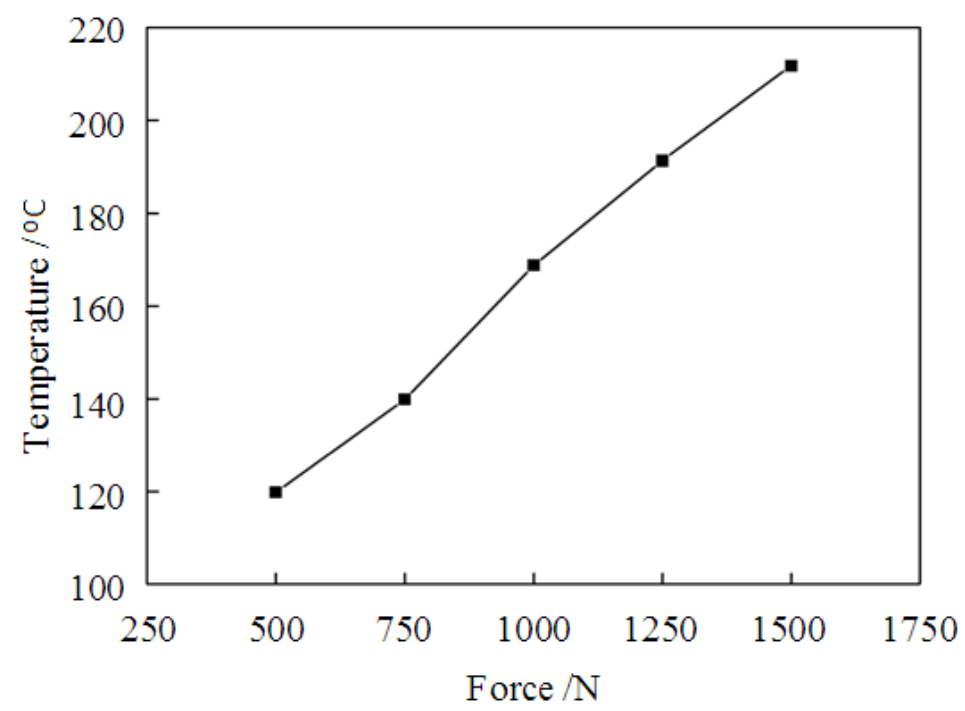

Figure 10: Maximum temperature change diagram with different grinding forces.

\subsection{Influence of force loading position on the temperature field}

To investigate the effect of loading position, the concentrated force was applied in two ways. Firstly, the concentrated force of $1000 \mathrm{~N}$ was loaded at the centre (F1 in Fig. 11). Secondly, the concentrated force of $500 \mathrm{~N}$ was loaded on each side (F2 in Fig. 11). Besides, the grinding speed was set as $60 \mathrm{~km} / \mathrm{h}$. 


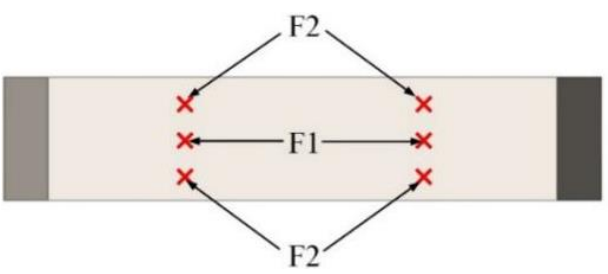

Figure 11: Grinding force loaded in the concentrated force at different positions.

When two concentrated forces were applied at the point of F1, the majority of the hightemperature areas on the rail surface was concentrated in the middle of the rail with the value of $139^{\circ} \mathrm{C}$, which was slightly higher than the average grinding temperature. When the concentrated force of two points was applied at the action point of F2, the pressure on the rail surface was relatively uniform because the grinding plate was set as rigid body without deformation. The temperature field distribution was similar to that under the applied uniform force. The two high-temperature regions were elongated and evenly distributed on the rail surface, and the highest temperature was $125.4{ }^{\circ} \mathrm{C}$ (Fig. 12).

The temperature distribution of the cross section was similar to that on the rail surface. The high-temperature zone had a large incoming depth, and the overall temperature decreased with the increase in the incoming depth and gradually realized the uniform distribution. According to the temperature field in the rail section (Fig. 13), the largest affected depth under the force loading position of F1 was about $2.88 \mathrm{~mm}$ and occurred at the middle of the rail. The largest affected depth for F2 was about $2.54 \mathrm{~mm}$ and occurred on the side of the rail at the edge of the high-temperature zone.

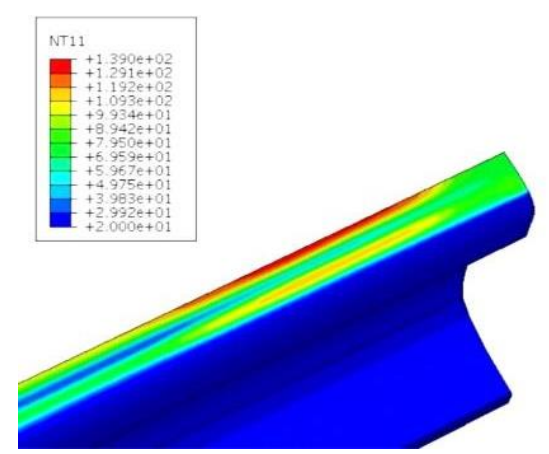

a) F1

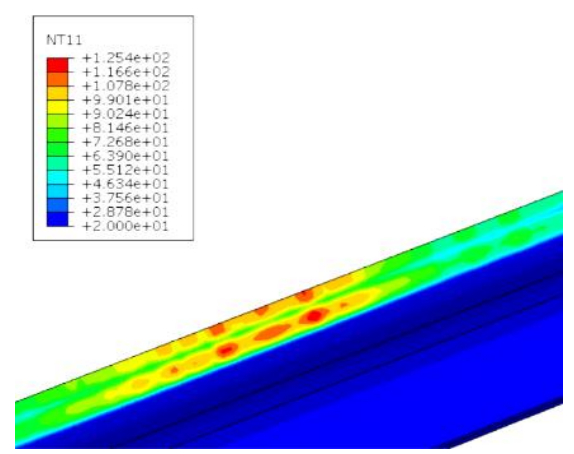

b) F2

Figure 12: Temperature distribution on the rail surface under different force loading positions.
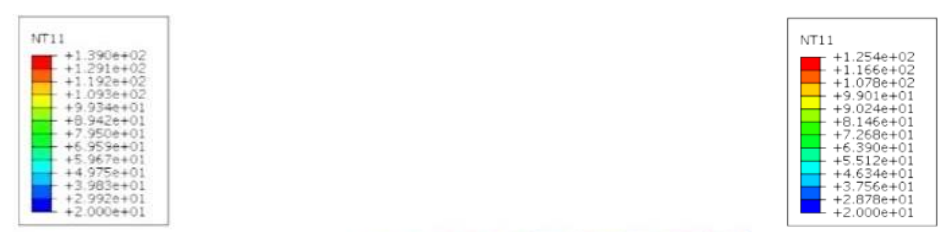

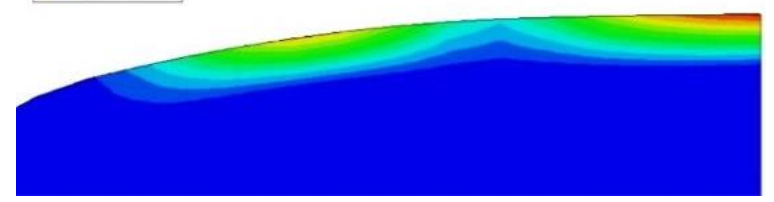

a) F1

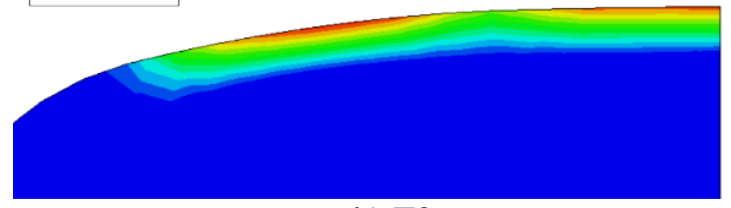

b) F2

Figure 13: Temperature distribution of the rail cross section under different pressure locations.

\subsection{Influence of the number of chip grooves on the temperature field}

The section aims to investigate the effect of the number of chip grooves. Under the same overall size of the pressing plate, the number of grooves increased, whereas the width of 
grooves was reduced. In addition to the original pressing plate (P2), two pressing plates with three (P3) and four grooves (P4) were introduced for the analysis.

The temperature distributions of $\mathrm{P} 3$ and $\mathrm{P} 4$ were different at the beginning compared with the case of P2 (Fig. 14). The sizes of temperature fields of P3 and P4 decreased and the decreasing trend corresponded to the variation of the contact zone between the abrasive belt and the rail. The increase in the grooves made the high-temperature zone more dispersed.

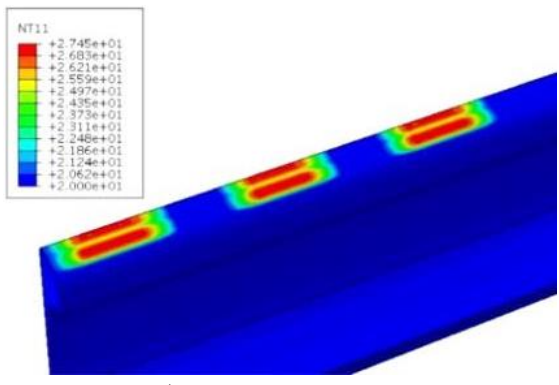

a) two grooves

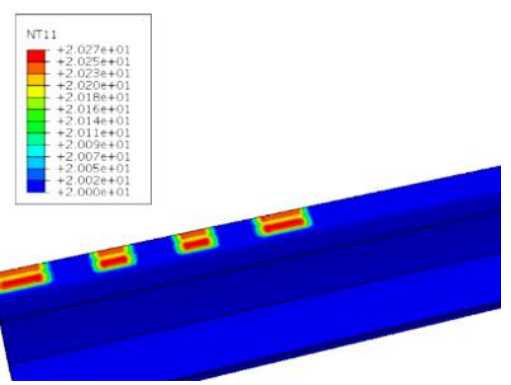

b) three grooves

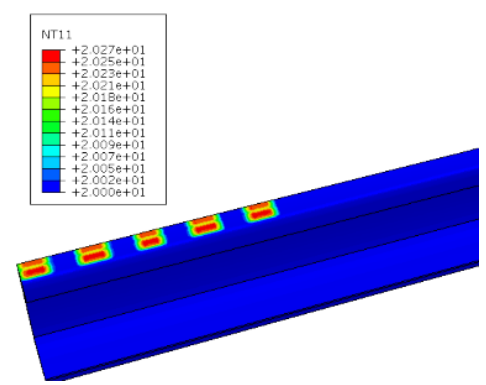

c) four grooves

Figure 14: Rail surface grinding temperature field.

The maximum temperature of all 3 cases had a similar changing mode (Fig. 15). Initially, the maximum temperature increased approximately linearly, and then fluctuated in a relatively stable range after reaching the peak. P1, P2 and P3 had a similar slope in the ascent stage. However, with the increase in the number of grooves, the maximum temperatures of P2, P3, and P4 decreased to $119.8{ }^{\circ} \mathrm{C}, 109.6{ }^{\circ} \mathrm{C}$ and $97.4{ }^{\circ} \mathrm{C}$, respectively. The difference might be interpreted as follows. With the increase in the number of grooves, the stressed area of the abrasive belt decreased, thus leading to the reduction in the generated heat and the temperature decline.

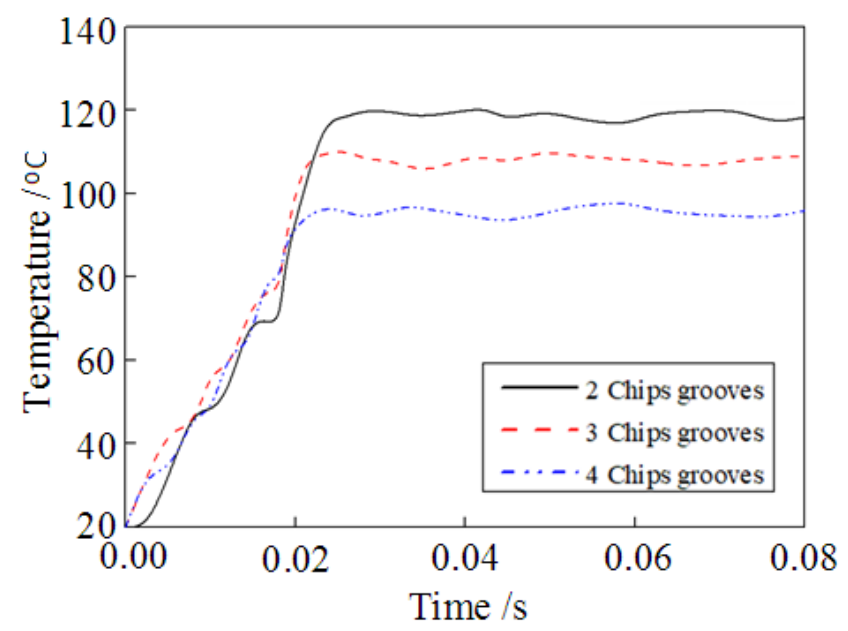

Figure 15: Temporal variation of the maximum temperature.

\section{CONCLUSIONS}

To investigate the temperature field induced by the grinding heat during ABRG-O, we established numerical abrasive belt topography and then analysed the grinding temperature with 3D FEM multi-abrasive scratching in the paper. The simulation results showed that the overall temperature field was rectangular and corresponded to the contact zone shape between the plate and the belt. The peak temperature grew up approximately linearly at the beginning and afterward fluctuated in a relatively stable range. Besides, the rising grinding force increased the area and intensity of the temperature field and induced a linear growth of the 
temperature peak value. The grinding force applied on two sides of the pressing plate could bring a more uniform lower-temperature field compared to that applied at the centre. Furthermore, adding chip grooves significantly reduced the peak value of the grinding temperature on the rail surface. However, it is difficult to realize the precise prediction through this numerical analysis and the further experimental investigation should be carried out in the future.

\section{ACKNOWLEDGEMENT}

The study was financially supported by the Fundamental Research Funds for the Central Universities (Grant No. 2019JBM050).

\section{REFERENCES}

[1] Fan, W. G.; Hou, G. Y.; Wang, W. X.; Zhang, X. L.; Wang, J. D. (2019). Design and dynamic analysis of a new rail grinding device using closed abrasive belt, International Journal of Simulation Modelling, Vol. 18, No. 3, 531-542, doi:10.2507/IJSIMM18(3)CO14

[2] Cuervo, P. A.; Santa, J. F.; Toro, A. (2015). Correlations between wear mechanisms and rail grinding operations in a commercial railroad, Tribology International, Vol. 82, Part B, 265-273, doi:10.1016/j.triboint.2014.06.025

[3] Zhi, S. D.; Li, J. Y.; Zarembski, A. M. (2015). Grinding motor energy saving method based on material removal model in rail grinding processes, International Journal of Precision Engineering and Manufacturing - Green Technology, Vol. 2, No. 1, 21-30, doi:10.1007/s40684$\underline{015-0003-1}$

[4] Zhi, S. D.; Li, J. Y.; Zarembski, A. M. (2016). Predictive modeling of the rail grinding process using a distributed cutting grain approach, Proceedings of the Institution of Mechanical Engineers, Part F: Journal of Rail and Rapid Transit, Vol. 230, No. 6, 1540-1560, doi:10.1177/0954409715605139

[5] Huang, Y.; He, S.; Xiao, G. J.; Li, W.; Jiahua, S. L.; Wang, W. X. (2020). Effects research on theoretical-modelling based suppression of the contact flutter in blisk belt grinding, Journal of Manufacturing Processes, Vol. 54, 309-317, doi:10.1016/j.jmapro.2020.03.021

[6] Huang, Y.; Jiahua, S. L.; Xiao, G. J.; He, Y.; Dai, W. T.; He, S.; Li, W. (2020). Study on the surface topography of the vibration-assisted belt grinding of the pump gear, International Journal of Advanced Manufacturing Technology, Vol. 106, No. 1-2, 719-729, doi:10.1007/s00170-01904645-7

[7] Fan, W. G.; Hou, G. Y.; Wang, W. X.; Wu, Y. F. (2019). Dynamic analysis of a novel railgrinding car using open-structured abrasive belt for high-speed railways, Mathematical Problems in Engineering, Vol. 2019, Paper 1748679, 9 pages, doi:10.1155/2019/1748679

[8] Fan, W. G.; Liu, Y. M.; Song, X. Y.; Chen, J. F.; Li, J. Y. (2018). Influencing mechanism of rubber wheel on contact pressure and metal removal in corrugated rail grinding by abrasive belt, Journal of Manufacturing Science and Engineering, Vol. 140, No. 12, Paper 124501, 8 pages, doi: $10.1115 / 1.4041243$

[9] Zhang, Z. Y.; Shang, W.; Ding, H. H.; Guo, J.; Wang, H. Y.; Liu, Q. Y.; Wang, W. J. (2016). Thermal model and temperature field in rail grinding process based on a moving heat source, Applied Thermal Engineering, Vol. 106, 855-864, doi:10.1016/j.applthermaleng.2016.06.071

[10] Jourani, A. (2015). Three dimensional modelling of temperature distribution during belt finishing, International Journal of Surface Science and Engineering, Vol. 9, No. 2/3, 231-246, doi:10.1504/IJSURFSE.2015.068237

[11] Wang, J. W.; Xu, J. J.; Wang, X. F.; Zhang, X. Q.; Song, X. F.; Chen, X. Q. (2019). A comprehensive study on surface integrity of nickel-based superalloy Inconel 718 under robotic belt grinding, Materials and Manufacturing Processes, Vol. 34, No. 1, 61-69, doi: $\underline{10.1080 / 10426914.2018 .1512137}$ 
[12] Huo, W. G.; Xu, J. H.; Fu, Y. C. (2008). The finite element analysis of surface temperature on dry belt grinding for titanium alloys, Advanced Materials Research, Vol. 53-54, 219-224, doi:10.4028/www.scientific.net/AMR.53-54.219

[13] Contuzzi, N.; Campanelli, S. L.; Ludovico, A. D. (2011). 3D finite element analysis in the selective laser melting process, International Journal of Simulation Modelling, Vol. 10, No. 3, 113-121, doi:10.2507/IJSIMM10(3)1.169

[14] Deng, W. J.; Xie, Z. C.; Li, Q.; Lin, P. (2013). Finite element modelling and simulation of chip breaking with grooved tool, International Journal of Simulation Modelling, Vol. 12, No. 4, 264275, doi:10.2507/IJSIMM12(4)5.250

[15] Wan, Q.; Zheng, M. L.; Yang, S. C.; Sun, J. K. (2019). Optimization of micro-texture distribution through finite-element simulation, International Journal of Simulation Modelling, Vol. 18, No. 3, 543-554, doi:10.2507/IJSIMM18(3)CO15

[16] Fang, C.; Xu, X. (2014). Analysis of temperature distributions in surface grinding with intermittent wheels, International Journal of Advanced Manufacturing Technology, Vol. 71, No. 1-4, 23-31, doi:10.1007/s00170-013-5472-1

[17] Wang, W. X.; Li, J. Y.; Fan, W. G.; Song, X. Y.; Wang, L. F. (2017). Characteristic quantitative evaluation and stochastic modeling of surface topography for zirconia alumina abrasive belt, International Journal of Advanced Manufacturing Technology, Vol. 89, No. 9-12, 3059-3069, doi: $10.1007 / \mathrm{s} 00170-016-9242-8$

[18] Wang, W. X.; Salvatore, F.; Rech, J.; Li, J. Y. (2018). Comprehensive investigation on mechanisms of dry belt grinding on AISI52100 hardened steel, Tribology International, Vol. 121, 310-320, doi:10.1016/j.triboint.2018.01.019

[19] Xiao, G. J.; He, Y.; Huang, Y.; Li, Q. (2019) Shark-skin-inspired micro-riblets forming mechanism of TC17 titanium alloy with belt grinding, IEEE Access, Vol. 7, 107635-107647, doi:10.1109/ACCESS.2019.2932725

[20] Rech, J.; Kermouche, G.; Grzesik, W.; Garcia-Rosales, C.; Khellouki, A.; Garcia-Navas, V. (2008). Characterization and modelling of the residual stresses induced by belt finishing on a AISI52100 hardened steel, Journal of Materials Processing Technology, Vol. 208, No. 1-3, 187195, doi:10.1016/j.jmatprotec.2007.12.133 